\title{
Antimicrobial Drug Resistance and Disinfectants Susceptibility of Pseudomonas aeruginosa Isolates from Clinical and Environmental Samples in Jimma University Specialized Hospital, Southwest Ethiopia
}

\author{
Meseret Mitiku ${ }^{1}$, Solomon Ali ${ }^{2}$, Gebre Kibru$^{2,}$, \\ ${ }^{1}$ Microbiology Department, Oromia Public Health Research and Quality Assurance Laboratory, Adama, Ethiopia \\ ${ }^{2}$ Department of Medical Laboratory Sciences and Pathology, Jimma University, Ethiopia
}

\section{Email address:}

mesmit03@yahoo.com (M. Mitiku),solali2005@gmail.com (S. Ali), gebre.tiga@ju.edu.et (G. Kibru)

\section{To cite this article:}

Meseret Mitiku, Solomon Ali, Gebre Kibru. Antimicrobial Drug Resistance and Disinfectants Susceptibility of Pseudomonas aeruginosa Isolates from Clinical and Environmental Samples in Jimma University Specialized Hospital, Southwest Ethiopia. American Journal of Biomedical and Life Sciences. Vol. 2, No. 2, 2014, pp. 40-45. doi: 10.11648/j.ajbls.20140202.12

\begin{abstract}
P. aeruginosa is one of the most important pathogen that causes nosocomial infections often acquired from hospital environment and contaminated medical devices. The infections caused by this bacterium are particularly problematic because it is inherently resistant to several unrelated antimicrobial agents and antiseptics. Hence, the aim of this study was to determine drug resistance and disinfectants susceptibility of $P$. aeruginosa isolated from clinical samples and hospital environments. A laboratory based cross sectional study was conducted from May to September, 2012 on a total of $81 P$. aeruginosa isolates. A standard bacteriological technique (conventional biochemical tests and pigment production) was used to identify the bacterium. Drug resistance and disinfectant susceptibility tests were determined by Kirby-Bauer disc-diffusion and through the classic method of successive dilutions respectively. In this study a total of 305 (160 clinical and 145 environmental) samples were investigated for $P$. aeruginosa and 81 isolates were obtained. This gives an overall $P$. aeruginosa isolation rate of $26.5 \%(81 / 305)$. About $47.5 \%$ of the clinical and $34.2 \%$ environmental isolates were detected from wounds and ward sinks respectively. Of these P. aeruginosa isolates, $95.1 \%$ were resistance to Trimethoprim-sulphametoxazole, $62 \%$ to Gentamicin, and $58 \%$ to Ceftriaxone. But, only $4.9 \%$ of isolates were resistance to Amikacin. Moreover, disinfectant susceptibility test revealed that hydrogen peroxide and sodium hypochlorite had a higher $(92.6 \% \& 91.4 \%)$ bactericidal activity compared to ethanol and savlon at the recommended user dilution. In general, our results indicated that $P$. aeruginos $a$ was significantly resistance to commonly prescribed antimicrobial drugs, a situation that demands a more rational and appropriate use of antibiotics. Hydrogen peroxide and sodium hypochlorite were relatively more effective when used in recommended dilution. However, all tested disinfectants or antiseptics showed reduced bactericidal activities in higher dilutions. Therefore, strict adherence to the recommended dilution is important for better activity. The correct use of them also has to be considered appropriately as part of infection control practices.
\end{abstract}

Keywords: P. aeruginosa, Drug resistance, Disinfectant susceptibility, Clinical and Environmental samples, Jimma

\section{Introduction}

Pseudomonas aeruginosa belongs to a vast genus of aerobic, non-fermenting, saprophytic, Gram-negative bacilli widespread in nature, particularly in moist environments [1].This bacterium is primarily a nosocomial pathogen responsible for $10-15 \%$ of nosocomial infections and $65 \%$ of mortality in hospitals all over the world [2]. Although it causes disease in healthy individuals, it is a major threat to hospitalized and immunocompromised patients, particularly those with diseases such as burns and cancer. The high mortality associated with these infections is due to a combination of weak host defense system and bacterial resistance to antibiotics [3]. Apart from the patient's predisposing factors, the risk of $P$. aeruginosa infection can be greatly increased by inadequate hospital 
hygiene. The hospital environment and contaminated medical devices have often been suggested as potential sources of infection [4]. As such, contaminated respiratory care equipment, irrigating solutions, catheters, infusions, dilute antiseptics, cleaning liquids, and even soaps have been reported as vehicles of transmission [1].

Naturally, this organism is endowed with weak pathogenic potentials. However, its profound ability to survive on inert materials, minimal nutritional requirement, tolerance to a wide variety of physical conditions and its relative resistance to several unrelated antimicrobial agents and antiseptics, contributes enormously to its ecological success and its role as an effective opportunistic pathogen [1]. Since the majority of $P$. aeruginosa strains are resistant to most of antibacterial agents, it is considered as one of the major problems in many hospitals [5]. These resistant strains establish themselves in the hospital environment in areas like sinks, taps, railing, mattress, toilets, and thereby spread from one patient to another. Its high rate for developing resistance against most of the antimicrobial agents have caused attention to be focused on measures for fighting resistance, foremost of which is susceptibility surveillance [6].

Antiseptics and disinfectants are used extensively in hospitals and healthcare settings for a variety of topical and hard surface applications. In particular, they are an essential part of infection control practices and aid in the prevention of nosocomial infections in general [7]. However, infections by $P$ aeruginosa are often difficult to treat because of its virulence, intrinsic and acquired antibiotic resistance, and limited choice for effective antimicrobial agents. It is also particularly resistant to biocides (disinfectants, antiseptics, and preservatives). Antibiotic resistance in bacteria has been subject of a great deal of research. By contrast biocide resistance is an emerging issue that is now attracting interest [8, 9]. The selection, use and control of the effectiveness of disinfectants have been emphasized, since environmental surfaces and medical and surgical instruments can serve as vehicles for infectious agents in susceptible hosts associated with the hospital setting [7].

Although different strategies are designed for the control of antimicrobial drugs and disinfectants resistance, most countries to date have focused on two main strategies: (i) the appropriate and prudent use of antimicrobial drugs and disinfectants both in hospitals and the community and (ii) good infection control practices again both in hospitals and the community [10]. Moreover, effective means to control antimicrobial drugs resistance is to develop a surveillance programme on a national and international level. This would be of great assistance, especially for forecasting future changes in the resistance of bacteria [11]. Therefore, this study aimed to assess pattern of drug resistance and disinfectant susceptibility of $P$. aeruginosa isolated from clinical and environmental samples. The findings of this study would indicate selection of proper antimicrobial agent for hospital use and better management of hospital infections.

\section{Materials and Methods}

\subsection{Study Design and Population}

A hospital based cross sectional study was conducted to assess the antimicrobial drugs and disinfectants susceptibility pattern of $P$. aeruginosa isolated from clinical and environmental samples. The study was undertaken from May 1 to September 30, 2012 in Jimma University Specialized Hospital (JUSH). It is the only referral hospital for over ten million people in the southwestern part of the country. The hospital provides almost all major types of medical care in its different departments. It is also a teaching hospital with a total capacity of about four hundred beds and eleven wards [12].

\subsection{Specimen Collection and Processing}

Clinical specimens such as urine, sputum and swabs from wounds/burns were collected from hospitalized and non-hospitalized patients attending in JUSH for various medical reasons. Environmental specimens from patients' beds, table tops, benches tops, door handles, and ward sinks were collected by rubbing moist sterile cotton swabs on these material surfaces. Then, the swabs were placed into test tubes having $0.5 \mathrm{ml}$ of normal saline solution and transported to the laboratory within $30 \mathrm{~min}$ to $1 \mathrm{hr}$ of collection (13).

Subsequently, both clinical and environmental specimens were inoculated on MacConkey agar (Oxoid, England) and incubated at $37^{\circ} \mathrm{C}$ for $18-24$ hours. Identification of $P$. aeruginosa was done using colony morphology, Gram-stain and conventional biochemical tests such as oxidase production, citrate utilization, and oxidative fermentation. Pigment production was confirmed by sub-culturing suspected colonies on nutrient agar (Oxoid, England) [13].

\subsection{Antimicrobial Drugs Susceptibility Testing}

The drug susceptibility testing of $P$. aeruginosa isolates was done by disc diffusion method following Clinical Laboratory Standards Institute (CLSI) guide lines [14]. Accordingly, 3-5 selected colonies of $P$. aeruginosa were taken from a pure culture and transferred to a tube containing $5 \mathrm{ml}$ sterile nutrient broth and mixed gently until a homogenous suspension was formed. The test organisms (bacterial isolates) was grown in nutrient broth and incubated for 4-6 hours at $37^{\circ} \mathrm{C}$ until the turbidity was matched with the $0.5 \mathrm{McF}$ arland standards. The bacteria suspension adjusted to McFarland turbidity was evenly swabbed over the entire surface of Mueller Hinton agar (Oxoid, England) using sterile cotton swab. The inoculated plates were then incubated at $37^{\circ} \mathrm{C}$ for 24 hours. Diameters of the zone of inhibition around the discs were measured to the nearest millimeter using a ruler, which was held on the back of the inverted petri plate, and the isolates were classified as sensitive, intermediate and resistant according to the standardized table supplied by the CLSI [14]. 
The drug discs were obtained from Oxoid, England, with the following concentrations: Amikacin (AN) $(30 \mu \mathrm{g})$, Ceftriaxone (CRO) $(30 \mu \mathrm{g})$, Gentamicin $(\mathrm{CN})(10 \mu \mathrm{g})$, Norfloxacin (NOR) $(10 \mu \mathrm{g})$, Ciprofloxacin (CIP) $(5 \mu \mathrm{g})$, Piperacillin (PIP) $(100 \mu \mathrm{g})$, Imipenem (IPM) $(10 \mu \mathrm{g})$, and Trimethoprim-sulphamethoxazole (SXT) $(1.25 / 23.75 \mu \mathrm{g}$ ). The criterion used to select the antimicrobial drugs was based on guideline provided by CLSI for the management of pseudomonas infections, their availability and from literatures search. The standard reference strain of $P$. aeruginosa (ATCC 27853) was used as a quality control for culture and susceptibility testing throughout the study.

\subsection{Disinfectants Susceptibility Testing}

There are several methods of testing susceptibility of a test organism to a given disinfectants/antiseptics or to ascertain potency and efficacy of a particular chemical antimicrobials. In this study the susceptibility of P.aeruginosa isolates were tested against Hydrogen peroxide $(3 \% \mathrm{w} / \mathrm{v})$, Sodium hypochlorite $(5 \% \mathrm{w} / \mathrm{v})$, Ethanol $(70 \% \mathrm{v} / \mathrm{v})$ and Savlon (1.5\% v/v Chlorhexidine + $15 \% \mathrm{w} / \mathrm{v}$ Cetrimide). The bactericidal concentration of these four commercial disinfectants and/or antiseptics was determined through the classic method of successive dilutions. In series of seven test tubes (which labeled as \# 1-7), $1 \mathrm{ml}$ of sterile nutrient broth was distributed into every tube, except tube \# 1 . Then, $1 \mathrm{ml}$ of disinfectant of known concentration was added into the $1^{\text {st }}$ and the $2^{\text {nd }}$ tubes of the series. The content in tube 2 was mixed and 1 $\mathrm{ml}$ mix was transferred into tube 3. This successive transference was repeated until tube 5 and at last $1 \mathrm{ml}$ of content from tube 5 was discarded into sink. Finally, $0.1 \mathrm{ml}$ of P.aeruginosa suspension was added to all tubes, except tube \# 7. Tube \#6 was used as positive control with its content (nutrient broth + test organism) and Tube \#7 as negative control (nutrient broth + distilled water). The contents of the tubes were then incubated at $35-37^{\circ} \mathrm{C}$ for 18-24 hours. At last, sub-culturing the contents of the tubes was made on nutrient agar and observed for bacterial growth after 24 hour of incubation at $35-37^{\circ} \mathrm{C}$. The bactericidal concentration was considered as the concentration of the tube in which no $P$. aeruginosa growth was seen after sub-culturing the contents of the tube on nutrient agar [15]. As a quality control, the standard reference strain of $P$. aeruginosa (ATCC 27853) was used in order to check quality of nutrient broth and all disinfectants were kept in the dark at room temperature and freshly prepared prior to testing.

\section{Data Analysis}

The relevant data was collectively documented on a questionnaire and analyzed using SPSS version 16.0.

\section{Results}

A total of 305 (160 clinical and 145 environmental) samples were investigated for $P$. aeruginosa. Correspondingly, 81 isolates ( 40 from clinical and 41 from environmental samples) were obtained with an overall isolation rate of $26.5 \%(81 / 305)$. Of those clinical isolates, $47.5 \%$ was identified from wounds, $37.5 \%$ from urine and $15 \%$ from sputum samples (Table 1 ).

Table 1. Frequency of $P$. aeruginosa isolates with respect to clinical specimen types at Jimma University Specialized Hospital, Jimma, Southwest Ethiopia (May-September 2012).

\begin{tabular}{lcc}
\hline Specimen & Specimens examined & $\begin{array}{c}\text { P. aeruginosa isolates; No. } \\
(\%)\end{array}$ \\
\hline Wound & 55 & $19(47.5)$ \\
Urine & 55 & $15(37.5)$ \\
Sputum & 50 & $6(15)$ \\
Total & 160 & $40(100)$ \\
\hline
\end{tabular}

Of those various environmental samples, the highest rate (34.2\%) of $P$. aeruginosa was detected in ward sinks, followed by door handles (26.8\%) and beds (19.5\%) (Table 2).

Table 2. Frequency of P. aeruginosa isolates with respect to housekeeping surfaces at Jimma University Specialized Hospital, Jimma, Southwest Ethiopia (May-September 2012).

\begin{tabular}{lcc}
\hline Site of collection & Samples examined & $\begin{array}{c}\text { P. aeruginosa isolates; } \\
\text { No. (\%) }\end{array}$ \\
\hline Ward sinks & 30 & $14(34.2)$ \\
Door handles & 29 & $11(26.8)$ \\
Patients' beds & 29 & $8(19.5)$ \\
Table tops & 29 & $5(12.2)$ \\
Bench tops & 28 & $3(7.3)$ \\
Total & 145 & $41(100)$ \\
\hline
\end{tabular}

The drug susceptibility testing profile of $P$. aeruginosa showed that, $95.1 \%$ of isolates were resistance to Trimethoprim-sulphametoxazole, $62 \%$ to Gentamicin, and $58 \%$ to Ceftriaxone. But, only $4.9 \%$ of isolates were resistance to Amikacin. The P.aeruginosa isolates from environments were more resistant to a particular drug than that of clinical isolates. However, the observed difference was not statistically significant $(\mathrm{P}>0.05)$ (Table 3 ).

Table 3. Antimicrobial drugs resistance of P.aeruginosa $(n=81)$ with respect to sample types at Jimma University Specialized Hospital, Jimma, Southwest Ethiopia (May-September 2012).

\begin{tabular}{lcccc}
\hline \multicolumn{5}{c}{ Sample types } \\
Drugs & $\begin{array}{c}\text { Clinical } \\
\text { isolates } \\
\text { No(\%) } \\
\text { Environment } \\
\text { al isolates } \\
\text { Nosistance }\end{array}$ & $\begin{array}{c}\text { Total } \\
\text { Nosistance }\end{array}$ & P-value \\
& $1(2.5)$ & $3(7.3)$ & $4(4.9)$ & 0.360 \\
\hline Amikacin & $22(55)$ & $28(68.3)$ & $50(62)$ & 0.221 \\
Gentamicin & $3(7.5)$ & $7(17.1)$ & $10(12.3)$ & 0.245 \\
Imipenem & $21(52.5)$ & $26(63.4)$ & $47(58)$ & 0.591 \\
Ceftriaxone & $2(5)$ & $7(17.1)$ & $9(11.1)$ & 0.224 \\
Piperacillin & $5(12.5)$ & $12(29.3)$ & $17(21)$ & 0.135 \\
Ciprofloxacin & $3(7.5)$ & $9(21.9)$ & $12(14.8)$ & 0.145 \\
Norfloxacin & & & & \\
Trimethopri- & $39(97.5)$ & $38(92.7)$ & $77(95.1)$ & 0.368 \\
sulphametoxa & & & & \\
zole & & & & \\
\hline
\end{tabular}

Moreover, the disinfectant susceptibility testing in this study confirmed that at user dilution $(0.5 \%$ concentration) 
of sodium hypochlorite showed lethal effect on $91.4 \%$ of the $P$. aeruginosa isolates. Similarly, Hydrogen peroxide at user dilution ( $3 \%$ concentration) was found to be effective against $92.6 \%$ of isolates. At its recommended dilutions, $2 \%$ Savlon $^{\circledR}$ and $70 \%$ ethanol exhibited bactericidal effect against $88.9 \%$ and $85.2 \%$ of $P$. aeruginosa isolates respectively (Table 4$)$.

Table 4. Disinfectants susceptibility of P. aeruginosa $(n=81)$ isolates from clinical and environmental samples in Jimma University Specialized Hospital, Jimma, Southwest Ethiopia (May-September 2012).

\begin{tabular}{|c|c|c|c|c|}
\hline \multirow[b]{2}{*}{ Dilutions } & \multicolumn{4}{|c|}{$\begin{array}{l}\text { No }(\%) \text { of isolates susceptible to } \\
\text { Disinfectants/antiseptics type }\end{array}$} \\
\hline & $\begin{array}{c}\text { Hydrogen } \\
\text { peroxide }\end{array}$ & $\begin{array}{c}\text { Sodium } \\
\text { hypochl } \\
\text { orite }\end{array}$ & Ethanol & Savlon $^{\circledR}$ \\
\hline User & $75(92.6)$ & $74(91.4)$ & $69(85.2)$ & $72(88.9)$ \\
\hline $\begin{array}{c}\text { (Recommended }{ }^{*} \\
1: 2\end{array}$ & $70(86.4)$ & $65(80.2)$ & $42(51.8)$ & $57(70.4)$ \\
\hline $1: 4$ & $44(54.3)$ & $61(75.3)$ & $0(0)$ & $35(43.2)$ \\
\hline $1: 8$ & $21(25.9)$ & $57(70.4)$ & $0(0)$ & $12(14.8)$ \\
\hline $1: 16$ & $5(6.2)$ & $52(64.2)$ & $0(0)$ & $1(1.2)$ \\
\hline $1: 32$ & $0(0)$ & $40(49.4)$ & $0(0)$ & $0(0)$ \\
\hline
\end{tabular}

*User dilution: Hydrogen peroxide-3\%; Sodium hypochlorite- 0.5\%; Ethanol-70\%; Savlon ${ }^{\circledR}-2 \%$

\section{Discussion}

In this study, $P$. aeruginosa was identified from all four specimen types (urine, wound, sputum and environmental swabs) with an overall isolation rate of $26.5 \%(81 / 305)$ reflecting the ubiquitous nature of the organism. This finding goes in agreement with the study in Cameroon where $25.5 \%$ detection rate was reported [1] but higher than $18.6 \%$ reported in Egypt [16]. In our study, the 25\% detection rate of $P$. aeruginosa in clinical specimens was not significantly different from that of $28.3 \%$ from environmental specimens $(\mathrm{P}>0.05)$. Similar results were reported in Cameroon [1] and Egypt [16]. Majority (90\%) of clinical P. aeruginosa isolates in present study were identified on samples taken from admitted patients. Such frequent isolation of $P$. aeruginosa from hospitalized patients substantiated its significant role in nosocomial infections.

In this study, the majority (34.2\%) of P. aeruginosa identified in the environmental samples were from ward sinks, which could be explained by the fact that the bacterium thrives very well at habitats with adequate amount of moisture. Door handle samples gave the next highest proportion (26.8\%) of isolates. In hospitals and other places of human habitation, door handles are the most common article of contact by the people. It is therefore not surprising thriving of high $P$. aeruginosa isolates in such sites since people with wet hands (water or sweat) may easily come into contact with it. The places with least number of isolates were the beds, tables and benches tops as these are places that are likely to be dry.

Resistance of P.aeruginosa to commonly used antimicrobial agents is becoming an increasing clinical problem and a recognized public health threat [3]. In the present study, the highest resistance rate of P.aeruginosa was observed for Trimethoprim-sulphamethoxazole which was $97.5 \%$ and $92.7 \%$ in clinical and environmental isolates respectively $(\mathrm{p}>0.05)$. This finding is in agreement with 87.5\% reported in Addis Ababa [17], 93.5\% in Bangladesh [18], 100\% in Iran [6] and Nigeria [19] each. The possible explanation for such high rate of resistance against Trimethoprim-sulphamethoxazole might be associated with its easily availability and indiscriminate usage.

The resistance rate of P.aeruginosa isolates in clinical and environmental isolates to Gentamicin was $55 \%$ and $68.3 \%$ respectively $(\mathrm{p}>0.05)$, with an overall resistance of $62 \%$. This finding goes in line with studies done in India (63\%) [20], Cameroon (66.7\%) [1], Egypt (67.5\%) [16] and Turkey $(57.5 \%)$ [21], but higher than reports from Jamaica (21.6\%) [22], Ghana (46\%) [23], Nigeria (53\%) [24] and Iran (52.2\%) [25]. Higher resistance rates were also reported from Jordan (72\%) [26], Bangladesh (77.3\%) [18], Saudi Arabia (85.3\%) [27] and Malaysia (94.3\%) [28]. Bacterial resistance to Gentamicin is mainly due to an enzymatic modification of the antibiotic as it was indicated by Poole K [29]. The widely use of this drug in the hospital setting may have also contributed for the high resistance rate seen in this study.

The rate (58\%) of resistance of the P.aeruginosa isolates to Ceftriaxone seen in this study is in agreement with documented in Addis Ababa (58.3\%) [17], Iran (58.3\%) [30], Egypt (63.3\%) [16] and Nigeria (65\%) [24]. However, relatively higher resistance rates were reported from Palestine (75\%) [31], Turkey (84.2\%) [21], Bangladesh (86.1\%) [18] and Nigeria (86.8\%) [19].The high level of resistance seen against Ceftriaxone may be due to difference in intense and indiscriminate usage of the drug in these countries.

Although $P$. aeruginosa resistance to antibiotics has been extensively studied in both clinical and environmental samples, only few reports were available on disinfectants/antiseptics activity against this bacterium. It is well known that Sodium hypochlorite is widely used for disinfection of environmental surfaces, including surfaces contaminated by blood spills [32]. In the present study, evaluation of the susceptibility of $P$. aeruginosa to the sodium hypochlorite disinfectant demonstrated that the recommended user dilution (with $0.5 \%$ free chlorine) was effective against $91.4 \%$ of the isolates. This finding showed that sodium hypochlorite stands as an effective disinfectant formulation against $P$. aeruginosa when used at the recommended concentration. This finding goes in line with study reports made in USA [33] and Brazil [34] where sodium hypochlorite, at a concentration of $0.5 \%$, was effective against $92.2 \%$ and $86 \%$ of $P$. aeruginosa isolates respectively.

Hydrogen peroxide $\left(\mathrm{H}_{2} \mathrm{O}_{2}\right)$ is a widely used biocide for disinfection and antisepsis [33]. In the current study, the chemical has showed bactericidal activity against $92.6 \%$ of $P$. aeruginosa isolates at the user dilution of 3\% concentration. This study also demonstrated that about $86.4 \%$ of tested 
isolates were susceptible at 1:2 dilutions $\left(1.5 \% \mathrm{H}_{2} \mathrm{O}_{2}\right)$ too.

Alcohols exhibit rapid broad-spectrum antimicrobial activity against vegetative bacteria, viruses, and fungi but bacterial spores. It is widely used for both hard-surface disinfection and skin antisepsis. Little is known about the specific mode of action of alcohols, but based on the increased efficacy in the presence of water; it is generally believed that they cause membrane damage and rapid denaturation of proteins, with subsequent interference with metabolism and cell lysis [33]. In this study a total of $85.2 \% \quad P$. aeruginosa isolates were killed at the recommended $70 \%$ concentration. This finding shows that resistance is developing for $70 \%$ ethanol, although it remains the disinfectant of choice in hospitals.

Savlon $^{\circledR}$ works well on minor cuts and abrasions, promoting fast healing and minimal scaring. In the present study, Savlon ${ }^{\circledR}$ exhibited bactericidal effect against $88.9 \%$ of $P$. aeruginosa isolates at the recommended dilution ( $2 \%$ concentration). The $1: 2$ dilutions ( $1 \%$ concentration) of it found to be effective against $70.4 \%$ of the isolates. Comparable finding was reported from study done in Nigeria where $61 \%$ of $P$. aeruginosa isolates were susceptible to the Savlon at 1\% concentration [35].

As indicated by McDonnell G. and Russell AD, reduced susceptibility of $P$. aeruginosa to any disinfectants can be associated with the ability of the bacterium to form biofilms. Growth within biofilms gives rise to extensive genetic diversity that, in turn, enhances the potential for resistance against disinfectants, which can be attributed to reduced access of antiseptic or disinfectant to underlying cell, modulation of the microenvironment and genetic exchange between cells in a biofilm, which enhances tolerance to antiseptics and disinfectant [33].

\section{Conclusion}

Our results indicated that P.aeruginosa was less susceptible to commonly prescribed antimicrobial drugs which is an indication of circulating high levels of drug resistance strains, a situation that demands immediate attention. In spite of this, Amikacin, Piperacillin and Imipenem showed very good activity so that these antibiotics seem to be a promising therapy for pseudomonas infection. Since, empirical treatments to pseudomonas infections provoke drug resistance; treatment is advised to be based on the result of culture and sensitivity.

In this study, sodium hypochlorite, hydrogen peroxide, Savlon ${ }^{\circledR}$ and ethanol were relatively most effective when used in recommended dilution. However, all tested disinfectants or antiseptics showed reduced bactericidal activities in higher dilutions. The impaired effectiveness of disinfectants is worrisome as they are critical components of intervention strategies used in clinical medicine for preventing the dissemination of nosocomial diseases and their applicability in community environments for personal hygiene. The reduced susceptibility probably occurs as a result of indiscriminate and constant use and misuse of a particular disinfectant for a long period of time. Therefore, strict adherence to the recommended dilution of these chemical agents is compulsory for better activity, and the correct use of them also has to be considered appropriately as part of infection control practices.

\section{Ethics}

Official permission was obtained from the Jimma University Specialized Hospital management committee for doing the study in the hospital and written informed consent was also obtained from patients prior to sampling. All laboratory tests were done free of charge and their results were communicated to patients respective physician or nurses for beneficiary measures and any information was kept confidential.

\section{Competing interests}

The authors declare that they have no competing interests.

\section{Acknowledgements}

The authors would like to thank Jimma University for the financial support, Adama Regional Laboratory for media, reagents and antibiotic discs support, Ethiopian Health and Nutrition Research Institute, Addis Ababa, for providing control strains.

\section{References}

[1] Ndip RN, Dilonga HM, Ndip LM, Akoachere JF, Akenji TN Pseudomonas aeruginosa isolates recovered from clinical and environmental samples in Buea, Cameroon: current status on biotyping and antibiogram. Trop Med Int Health 2005; 10: 74-81.

[2] Strateva T, Raykova VO, Markova B, Todorova A, Proevska YM, Mitov I. Problematic clinical isolates of Pseudomonas aeruginosa from the university hospitals in Sofia, Bulgaria: current status of antimicrobial resistance and prevailing resistance mechanisms. J Med Microbiol 2007; 56: 956-963.

[3] Meenakumari S, Verma Sh, Absar A, Chaudhary A. Antimicrobial susceptibility pattern of clinical isolates of Pseudomonas aeruginosa in an Indian cardiac hospital. Int $J$ Engin Sci Technol 2011; 3: 7117- 7124.

[4] Orsi GB, Tomao P, Visca P. In vitro activity of commercially manufactured disinfectants against Pseudomonas aeruginosa. Eur J Epidemiol 1995; 11: 453-457.

[5] Kamel GM, Eldeen NA, Yousef M, Ezzat RF. Susceptibility pattern of Pseudomonas aeruginosa against antimicrobial agents and some plant extracts with focus on its prevalence in different sources. Global Veterinaria 2011; 6: 61-67.

[6] Haghi M, Maadi H, Delshad R, Nezhady M, Golizade S. Antibiotic resistance pattern of Escherichia coli, Staphylococcus aureus and Pseudomonas aeruginosa isolated from burnt patients Urmia, Iran. Int $J$ Acad Res 2010; 2 : 377- 380 . 
[7] Ogbulie JN, Adieze IE, Nwankwo NC. Susceptibilty pattern of some clinical bacterial isolates to selected antibiotics and disinfectants. Polish J Microbiol 2008; 57: 199-204.

[8] Romao CM, Faria YN, Pereira L, Asensi M. Susceptibility of clinical isolates of multiresistant Pseudomonas aeruginosa to a hospital disinfectant and molecular typing. Mem Inst Oswaldo Cruz 2005; 10: 541-548.

[9] Pal RB, Rodrigues M, Datta S. Role of Pseudomonas in nosocomial infections and biological characterization of local strains. J Biosci Tech 2010; 1: 170-179.

[10] World Health Organization. Antimicrobial resistance monitoring programme. WHO Drug Information 1997; 11; 248-249.

[11] Hawkey PM. Action against antibiotic resistance: no time to lose. Lancet 1998; 351: 1298-1299.

[12] Negussie D, Mesfin N. Review of maternal death in Jimma University Specialized Hospital. Ethiop J Health Sci 2009; 19: 9-12.

[13] Cheesbrough M. District Laboratory Practice in Tropical Countries Part II. 2nd ed. Cambridge University Press, Cambridge, 2006. 63-70.

[14] Clinical and Laboratory Standards Institute. Performance standards for antimicrobial susceptibility testing: 20th informational supplement (M100-S20). Wayne, PA; 2010.

[15] Mazzola PG, Jozala AF, Novaes LC, Moriel P, Penna TC. Minimal inhibitory concentration (MIC) determination of disinfectant and/or sterilizing agents. Braz J Pharm Sci 2009; 45: $241-248$.

[16] Gad GF, El-Domany RA, Zaki S, Ashour HM. Characterization of Pseudomonas aeruginosa isolated from clinical and environmental samples in Minia, Egypt: prevalence, antibiogram and resistance mechanisms. $J$ Antimicrob Chemother 2007; 60: 1010-1017.

[17] Tekie K. Surgical wound infection in Tikur Anbessa hospital with special emphasis on Pseudomonas aeruginosa. MSc Thesis. 2008

[18] Rashid A, Chowdhury A, Rahman HZ, Begum SA, Muazzam N. Infections by Pseudomonas aeruginosa and antibiotic resistance pattern of the isolates from Dhaka Medical College Hospital. Bangladesh J Med Microbiol 2007; 1: 48-51.

[19] Okon KO, Agukwe PC, Oladosu W, Balogun ST, Uba A. Antibiotic resistance pattern of Pseudomonas aeruginosa isolated from clinical specimens in a tertiary hospital in northeastern Nigeria. Internet J Microbiol 2010; 8: 316-321.

[20] Rakesh MR, Govind LN, Kalpesh M, Rosy P, Kanu P, Vegad MM. Antibiotic resistance pattern in Pseudomonas aeruginosa species isolated at a Tertiary Care Hospital, Ahmadabad. National J Med Res 2012; 2: 156-159.

[21] Gonlugur U, Bakici MZ, Ozdemir L, Akkurt I, Icagasioglu S, Gultekin F. Retrospective analysis of antibiotic susceptibility patterns of respiratory isolates of Pseudomonas aeruginosa in a Turkish University Hospital. Ann Clin Microbiol Antimicrob 2003; 2:5.
[22] Brown PD, Izundu A. Antibiotic resistance in clinical isolates of Pseudomonas aeruginosa in Jamaica. Am J Pub Health 2004; 16: 125-30.

[23] George DF. Antibiotic resistance patterns of Pseudomonas aeruginosa and Escherichia coli isolates from three hospitals in Kumasi, Ghana. MSc thesis. 2011.

[24] Jombo GT, Jonah P, Ayeni A. Multidrug resistant Pseudomonas aeruginosa in contemporary medical practice: findings from urinary isolates at a Nigerian University Teaching Hospital. Nigerian J Physiological Sci 2008; 23: 105-109.

[25] Hashemi SH, Mamani M, Omidi J, Niayesh A. Nosocomial bacterial infections and their antimicrobial resistance patterns in university hospitals of Hamedan, Iran. JRHS 2010; 10: 54-58.

[26] Masaadeh HA, Jaran AS. Incident of Pseudomonas aeruginosa in post-operative wound infection. Am J Infect Dis 2009; 5: 1-6.

[27] Salih HA, Abdulbary M, Abdulrida AS. Susceptibility of Pseudomonas aeruginosa isolated from urine to some antibiotics. J Vet Med Sci 2011; 10: 33-36.

[28] Al-Kabsi AM, Yusof M, Sekaran Sh. Antimicrobial resistance pattern of clinical isolate of Pseudomonas aeruginosa in the University of Malaya Medical Center, Malaysia. Afr J Microbiol Res 2011; 5: 5266-5272.

[29] Poole K. Aminoglycoside resistance in Pseudomonas aeruginosa. Antimicrob Agents Chemother 2005; 49: 479487.

[30] Mohammadi-mehr M, Feizabadi MM. Antimicrobial resistance pattern of Gram-negative bacilli isolated from patients at ICUs of Army hospitals in Iran. Iran J Microbiol 2011; 3: 26-30.

[31] Afifi AM, Moati A, Jarosha Kh, Samaha AS, Jadba AN. Nosocomial infections due to multidrug resistant Pseudomonas aeruginosa. J Al Azhar University 2007; 9: 112.

[32] Ekizoglu MT, Özalp M, Sultan N, Gür D. An investigation of the bactericidal effect of certain antiseptics and disinfectants on some hospital isolates of Gram-negative bacteria. Infect Control Hosp Epidemiol 2003; 24: 224-226.

[33] McDonnell G, Russell AD. Antiseptics and Disinfectants: activity, action, and resistance. Clin Microbiol Rev 1999; 12: 147-179.

[34] Bouzada ML, Silva VL, Moreira FA, Silva GA, Diniz CG. Antimicrobial resistance and disinfectants susceptibility of persistent bacteria in a tertiary care hospital. J. Microbiol Antimicrob 2010; 2: 105-112.

[35] Iroha IR, Oji AE, Nwosu OK, Amadi ES. Antimicrobial activity of Savlon, Izal and Z-germicide against clinical isolates of Pseudomonas aeruginosa from hospital wards. Eur J Dent Med 2011; 3: 32-35. 